\title{
USO DE RESÍDUO EM CONCRETO LEVE: UMA OPÇÃO SUSTENTÁVEL
}

\section{USE OF WASTE ON LIGHTWEIGHT CONCRETE: A SUSTAINABLE OPTION}

Eric Renã Zavitzki Schimanowski'; Gabrielli Tápia de Oliveira²; Diorges Carlos Lopes ${ }^{3}$.

${ }^{1}$ Graduando em Engenharia Civil, Universidade Regional do Noroeste do Estado do Rio Grande do Sul (UNIJUÍ). E-mail: eric.schimanowski@sou.unijui.edu.br

${ }^{2}$ Graduanda em Engenharia Civil, UNIJUÍ. E-mail: gabrielli.oliveira@ sou.unijui.edu.br

${ }^{3}$ Docente do curso de Engenharia Civil, UNIJUÍ. E-mail: diorges.lopes@unijui.edu.br

\section{PALAVRAS CHAVE}

Sílica da cinza da casca de arroz; Sustentabilidade; Argila expandida; Desempenho mecânico.

\section{KEY WORDS}

Silica of rice husk ash; Sustainability; Expanded clay; Mechanical performance.

\section{RESUMO}

Visando a análise de materiais alternativos no concreto, em busca de maior sustentabilidade na construção civil, foram moldados corpos de prova cilíndricos de concreto leve com substituições parciais, em massa, de $30 \%$ e $70 \%$ do agregado graúdo por argila expandida (AE) realizando, também, adições de $20 \%$ de sílica da cinza da casca de arroz (SCCA) em relação à massa do aglomerante. A partir disso, tem-se como objetivo avaliar a viabilidade técnica de concretos leves com AE com e sem adições de SCCA a partir da obtenção da massa específica e resistência à compressão através de ensaios laboratoriais. Quanto à compressão os concretos leves que utilizaram SCCA obtiveram melhores resultados, entretanto, ainda inferiores à referência.

\begin{abstract}
In order to analyze alternative materials in concrete, looking for sustainability in civil construction, cylindrical specimens of lightweight concrete were molded with partial substitutions, in mass, of 30\% and $70 \%$ of the coarse aggregate by expanded clay (AE), also making additions of $20 \%$ of silica from rice husk ash (SCCA) in relation to the mass of the binder. From this, the objective is to evaluate the technical viability of lightweight concrete with AE with and without SCCA additions obtaining the specific mass and compressive strength through laboratory tests. As for compression, lightweight concretes that used SCCA obtained better results, however, still lower than the reference.
\end{abstract}




\section{INTRODUÇÃO}

Apesar do concreto de cimento Portland ser o segundo material mais empregado no mundo, ficando atrás apenas da água, tem-se que essa mistura não apresentou grandes inovações até os anos 1980 (HELENE e ANDRADE, 2010). Nesse cenário, Rossignolo (2009) explica que isso se deu devido à ausência de métodos e equipamentos para a realização de testes que proporcionassem um melhor entendimento do comportamento do concreto quando incorporados novos materiais.

Com o desenvolvimento tecnológico atual, tornou-se possível realizar ensaios e análises que permitem a fabricação, com segurança, de concretos especiais, ou seja, que possuem constituintes alternativos. Ressalta-se, ainda, que algumas dessas misturas surgiram com o intuito de aprimorar características que limitam as aplicações do concreto como, por exemplo, a elevada massa específica desse material que tende a gerar elevados esforços de peso próprio sobre as estruturas. Nesse contexto, Rossignolo (2009) sugere o concreto leve como uma alternativa a ser considerada objetivando reduzir o peso, bem como facilitar o transporte e manuseio de peças préfabricadas.

Ademais, dentre as diversas formas existentes para fabricação do concreto leve, tem-se que a mais utilizada se refere à implementação de vazios na mistura por meio da substituição dos agregados convencionais por agregados leves como, por exemplo, a substituição da brita por argila expandida (ROSSIGNOLO, 2009). Essa argila apresenta elevada porosidade e formato arredondado, impactando diretamente nas propriedades do concreto como a trabalhabilidade, desempenho mecânico e durabilidade (MEHTA e MONTEIRO, 2006).

Assim, a porosidade desse material requer um consumo de água superior ao determinado pelo cálculo de dosagem. Isso se dá objetivando manter uma trabalhabilidade adequada e, portanto, gera um fator água/cimento elevado que impacta significativamente nas propriedades da pasta. Mehta e Monteiro (2006) sugerem, para atenuar essa situação, o uso de uma quantidade superior de cimento.

Entretanto, do ponto de vista ambiental, essa medida não é recomendada, visto que o cimento Portland gera altas quantidades de gases poluentes durante sua produção. Ademais, do ponto de vista econômico, o maior consumo de cimento torna o valor do concreto mais elevado, uma vez que esse é o componente mais caro da mistura. Nesse cenário, Neville (2016) aponta a possibilidade de incorporação de outro material com características cimentícias, como a sílica, a fim de promover a melhora do desempenho mecânico de concretos produzidos com agregados leves.

Outrossim, entendendo a responsabilidade da construção civil para com o meio ambiente, o concreto pode ser entendido como uma alternativa para promover a sustentabilidade através da incorporação de resíduos no mesmo. Nesse sentido, pode-se mencionar a casca de arroz, um subproduto que, quando adequadamente processado, pode se tornar uma fonte de sílica (FOLLETO et al. 2005). Esse material, ao ser empregado no concreto, pode auxiliar na formação de compostos cimentícios, visto que apresenta características pozolânicas.

A partir disso, essa pesquisa visa contribuir para a melhor compreensão de concretos especiais, mais especificamente o concreto leve, através da análise do impacto da argila expandida, bem como do uso da sílica da cinza da casca de arroz (SCCA) na mistura. O estudo se deu por meio da substituição parcial, em massa, de $30 \%$ e $70 \%$ do agregado graúdo por argila expandida e, também, da adição de $20 \%$ 
de SCCA em relação à massa de cimento. Posteriormente, foram realizados ensaios laboratoriais nos estados fresco e endurecido do concreto objetivando definir sua massa específica e consistência e, também, seu desempenho mecânico frente à compressão axial simples.

\section{REFERENCIAL TEÓRICO}

\subsection{Concreto}

O concreto conhecido como convencional é aquele constituído por uma pasta de cimento Portland que envolve agregados de diferentes dimensões (HELENE e ANDRADE, 2010). Para Mehta e Monteiro (2006), a ampla aplicação do concreto ocorre devido à fácil moldagem de estruturas em diversas formas e tamanhos, à trabalhabilidade e à durabilidade do material. Entretanto, embora apresente inúmeras vantagens que justifiquem o seu uso, a massa específica do concreto de cimento Portland pode limitar a sua aplicação. Para Neville (2016) essa propriedade impacta no peso próprio dos elementos de concreto, resultando no aumento dos custos da edificação.

A partir disso, o concreto leve surge como uma alternativa ao convencional, visto que diminui o peso específico das edificações gerando economia com fôrmas e cimbramento além da diminuição de custos para montagem e transporte de peças pré-fabricadas (ROSSIGNOLO, 2009). Ademais, Neville (2016) também salienta que a redução dos esforços solicitantes tende a diminuir as dimensões das fundações, gerando economia. Isso porque, como indica Rossignolo (2009), a característica primordial dos concretos leves é a redução da massa específica, sendo necessário valor inferior a $2000 \mathrm{~kg} / \mathrm{m}^{3}$ para essa propriedade.

Nesse sentido, cabe salientar que não há um consenso sobre os valores de massa específica que caracterizam um concreto como leve. Para Mehta e Monteiro (2006) e Neville (2016), o concreto leve é aquele que possui massa específica inferior a $1850 \mathrm{~kg} / \mathrm{m}^{3}$. Já para a ABNT NBR NM 35 (1995) o valor obtido não deve ultrapassar $1840 \mathrm{~kg} / \mathrm{m}^{3}$ sendo necessário, também, observar a resistência à compressão do concreto para garantir a segurança da estrutura. Ademais, embora existam várias classificações, todos os autores supracitados concordam que o concreto leve consiste na inserção de ar na mistura.

Neville (2016) evidencia que existem três formas de inserir ar na mistura e, assim, fabricar concretos leves. A primeira se dá por meio da utilização de aditivos incorporadores de ar, que originam concretos leves denominados celulares. A segunda forma ocorre através da retirada de materiais finos da mistura. Já a terceira ocorre pela substituição, total ou parcial, dos agregados convencionais (brita e areia) por agregados leves e porosos (ROSSIGNOLO, 2009).

Outrossim, tem-se que apenas a última forma é capaz de gerar concretos leves estruturais devido, principalmente, à resistência à compressão oferecida pelo agregado (ROSSIGNOLO, 2009). Para Neville (2016) a principal característica desse concreto é a massa específica baixa, resultante da alta porosidade em seu interior sendo que o autor recomenda a utilização de argila expandida como agregado leve devido, principalmente, ao controle existente na produção desse material.

\subsubsection{Cimento Portland}

$\mathrm{O}$ aglutinante mais utilizado no mundo para a fabricação de concreto é o cimento Portland, definido por Mehta e Monteiro (2006) como um material seco com partículas de pequeno diâmetro que, quando reagem quimicamente com a água, geram um composto aglutinante. Dessa forma, o cimento Portland é formado 
principalmente de silicatos hidráulicos de cálcio, contendo sulfato de cálcio natural, podendo conter, ainda, substâncias que modificam suas propriedades ou que facilitam sua utilização (BAUER, 2008).

\subsubsection{Sílica da cinza da casca de arroz}

Para Folleto et al. (2005), a geração de energia através da queima da casca de arroz é uma alternativa aplicável do ponto de vista tecnológico, economicamente viável e ecologicamente correta. Assim, para os autores, a utilização da SCCA faz com que exista um total aproveitamento no ciclo de industrialização do arroz, gerando resíduo zero. Ademais, a necessidade de encontrar aplicações para esse material se justifica na medida em que, quando descartada no meio ambiente, a SCCA provoca poluição devido ao carbono residual presente (FOLLETO et al. 2005).

A partir disso, é importante mencionar que a cinza possui alto teor de sílica e, ao ser produzida com controle, gera um resíduo nobre, conhecido como sílica da cinza da casca de arroz (SCCA). Esse material pode ser observado na Figura 1.

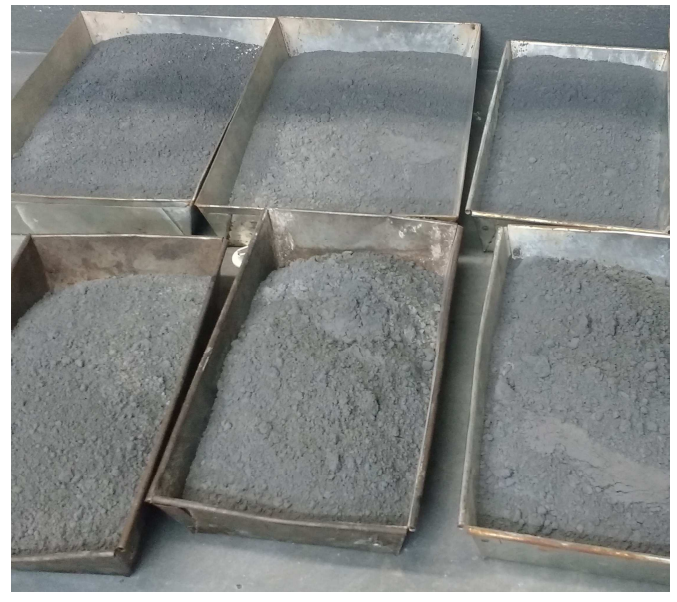

Figura 1. Sílica da cinza da casca de arroz utilizada na pesquisa. Fonte: Autoria própria (2019).
Na construção civil, esse material pode ser empregado na fabricação do concreto, como adição cimentícia, visto que o mesmo pode ser considerado altamente pozolânico (ZHANG e MALHOTRA, 1996). Nessa perspectiva, além de reduzir indiretamente as emissões de $\mathrm{CO}_{2}$ devida à menor utilização de cimento Portland, a SCCA pode agregar vantagens ao concreto produzido.

Em um estudo realizado por Schimanowski et al. (2019), em que o cimento Portland foi substituído pela SCCA, observou-se que pequenas quantidades do material, como substituições de $10 \%$, auxiliam no ganho de resistência à compressão em idades avançadas. Ademais, Mehta e Monteiro (2006) salientam que a superfície específica desse aglomerante alternativo é significativamente maior que a superfície do cimento Portland, implicando em maiores adições de água na mistura.

Por fim, Zhang et al. (1996), após realizarem estudo comparativo entre concretos com e sem substituição de cimento Portland por SCCA, concluíram que a mesma reduziu a porosidade na zona interfacial entre matriz e agregado e, também, sua largura. Isso afetou a resistência à compressão, gerando melhorias nos resultados obtidos.

\subsubsection{Agregados convencionais}

Os agregados são materiais particulados com atividade química quase nula, compostos por partículas que possuem diferentes tamanhos (BAUER, 2008). Sabendo disso, Neville (2016) salienta que as características dos agregados devem ser determinadas, já que esses materiais ocupam grande parte do volume final do concreto. Assim, podem influenciar em diversas propriedades da mistura como trabalhabilidade, massa específica, resistência mecânica, durabilidade, entre outras.

Embora existam diversas classificações possíveis para os agregados, que levam em 
consideração origem, massa específica e dimensões, Neville (2016) aponta que a propriedade de maior interesse é a granulometria. Segundo a ABNT NBR 7211 (2009) os agregados podem ser classificados em miúdos ou graúdos. A normativa técnica salienta, também, que, durante o ensaio de granulometria, os agregados miúdos são aqueles que passam na peneira com abertura de malha de 4,75 mm, e os graúdos são aqueles que ficam retidos.

\subsubsection{Argila expandida}

A argila expandida é um agregado artificial produzido através da exposição de argilas piroexpansivas a fontes de calor em altas temperaturas (AMBROZEWICZ, 2012). Assim, conforme Rossignolo (2009), no tratamento térmico as matérias primas sofrem fusão incipiente e, dessa forma, ocorre a expansão do material devido a geração de gases que ficam aprisionados no interior da estrutura, mantendo-a porosa após seu resfriamento. Na Figura 2 a argila expandida pode ser observada.

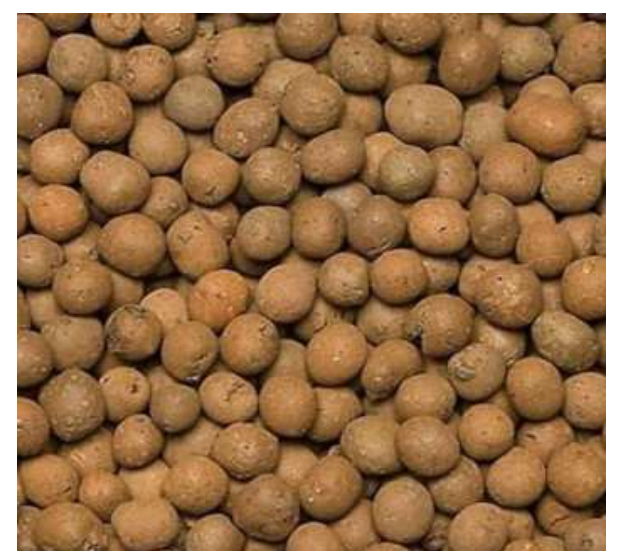

Figura 2. Argila expandida. Fonte: Cinexpan (2015).

Rossignolo (2009) salienta, também, que a argila expandida é o único agregado leve produzido no Brasil. Essa pode ser obtida através de dois processos de fabricação denominados forno rotativo e sinterização. No primeiro procedimento, parte da argila se funde em uma massa viscosa enquanto a outra parte se decompõe quimicamente de forma que os gases liberados expandam o material sendo que, por fim, há a formação de uma camada vitrificada externa reduzindo a absorção de água (MORAVIA et al. 2006).

Já na sinterização, Moravia et al. (2006) apontam que a argila é umedecida e transportada através de uma esteira sobre queimadores. Isso promove um contato gradual do material com o calor, fazendo com que a superfície final do agregado seja porosa e absorva mais água.

Ademais, a argila expandida é fabricada em diversas granulometrias. Para aplicação na construção civil, pode ser encontrada comercialmente nas numerações 2215, 1506 e 0500, sendo as dimensões dos materiais equivalentes, respectivamente, à brita 1 , brita 0 e areia grossa.

Para Moncada et al. (2019) a utilização da argila expandida 1506 apresenta vantagens como, por exemplo, a densidade até 2,5 vezes inferior à brita e, também, sua inércia química, evitando reações adversas sobre a armadura e a pasta de cimento. Ademais, o uso desse agregado pode influenciar outras propriedades do concreto como estabilidade dimensional, isolamento termoacústico, resistência mecânica, trabalhabilidade e módulo de deformação (ROSSIGNOLO, 2009).

\subsection{Propriedades do concreto}

É possível conceituar a palavra "propriedades" como as características, sejam essas físicas ou químicas, que devem ser observadas de modo a entender o comportamento e diferenciar os materiais existentes na mistura. Quanto ao concreto, Sobral (2000) ressalta que suas características no fresco e endurecido estão intimamente relacionadas. 


\subsubsection{Estado fresco}

A normativa ABNT NBR 12655 (2015, p. 03) define que o concreto no estado fresco é aquele "concreto que está completamente misturado e que ainda se encontra em estado plástico, capaz de ser adensado por um método escolhido". Nessa perspectiva, entender as características da mistura nesse estado permite que sejam analisadas as possibilidades para transporte, lançamento, adensamento e acabamento em obra (NEVILLE, 2016). A partir disso, para a presente pesquisa foram observadas a massa específica e a consistência dos traços definidos.

Em relação à massa específica, buscou-se entender o impacto gerado pelo agregado leve incorporado nas misturas a partir da comparação entre os resultados obtidos para essas e para o concreto convencional. Mehta e Monteiro (2006) ressaltam que o objetivo principal do concreto leve é a diminuição de peso, mesmo que os valores para desempenho mecânico fiquem prejudicados. Os mesmos autores evidenciam que a resistência à compressão do concreto é diretamente influenciada pelo emprego de agregados leves, geralmente reduzindo-a. Entretanto, ainda é possível fabricar concretos leves suficientemente seguros para emprego em fins estruturais.

Para Sobral (2000) a trabalhabilidade é a propriedade mais importante do concreto quando no estado fresco, visto que essa envolve a adequação da mistura ao tipo de obra a que se destina, à ausência de segregação ou exsudação e à adequada compactação. Rossignolo (2009) sugere que a argila expandida tende a absorver altas quantidades de água devido à sua porosidade interna, logo, a fim de evitar que a trabalhabilidade de concretos com esse material fique comprometida, deve ser realizada sua présaturação. Essa medida promove um aumento da relação água/cimento, logo, também impacta no desempenho mecânico dos elementos.

\subsubsection{Estado endurecido}

A normativa ABNT NBR 12655 (2015, p. 03) define que o concreto no estado endurecido é aquele "concreto que se encontra no estado sólido e que desenvolveu resistência mecânica". Frente ao desempenho mecânico, Helene e Andrade (2010) salientam que, em estruturas de concreto armado, a resistência à compressão deve ser meticulosamente avaliada a fim de identificar se os elementos cumprem os requisitos de segurança. Nessa perspectiva, o presente estudo visa à obtenção de valores referentes à resistência à compressão axial, comparando os dados obtidos para os traços com argila expandida com e sem adição de SCCA ao traço referência.

Mehta e Monteiro (2006) ressaltam que a porosidade é inversamente proporcional à resistência obtida e, para concretos convencionais, tem-se que a zona de transição e a porosidade da matriz cimentícia são fatores limitadores quanto ao desempenho das misturas. Ademais, os mesmos autores sugerem que, dentre os diversos fatores que impactam na resistência, um dos parâmetros mais importantes diz respeito à relação água/cimento que, por sua vez, determina a porosidade da pasta e limita sua resistência.

No caso da utilização de sílica da cinza da casca de arroz, Mehta (1992) conclui que é possível substituir mais de $70 \%$ do cimento por esse material pozolânico, entretanto, adições de $10 \%$ a $20 \%$ já são suficientes para que haja redução de permeabilidade e ganhos de resistência mecânica. Ademais, esse aumento no desempenho se dá em idades avançadas, visto que, por ser um material pozolânico, a SCCA possui reações que ocorrem de forma mais lenta. 


\section{MATERIAIS E MÉTODOS}

Para calcular o traço de dosagem foi necessário encontrar as propriedades dos materiais constituintes. Assim, a seguir serão descritos os ensaios realizados para o cimento Portland, areia, brita e argila expandida, bem como o traço definido a partir do método da Associação Brasileira de Cimento Portland (ABCP). Por fim, os ensaios realizados no concreto no estado fresco e no estado endurecido também serão discutidos.

\subsection{Caracterização dos materiais}

O aglomerante utilizado foi o Cimento Portland CP-V-ARI, caracterizado pelo alto ganho de resistência nas idades iniciais. Ademais, para a dosagem foi determinada a massa específica do material pela norma ABNT NBR 16605 (2017). Quanto à SCCA utilizada nesse estudo foram retirados dados de bibliografias que utilizaram o mesmo material.

Para os agregados foi utilizada a brita 0 e a areia grossa disponibilizados pelo Laboratório de Engenharia Civil da universidade. Assim, foi determinada a massa unitária dos agregados e a granulometria pelas normas ABNT NBR NM 45 (2006) e ABNT NBR 248 (2003), respectivamente. Ademais, também foi determinada a massa específica do agregado graúdo através da norma ABNT NBR NM 53 (2009) e do agregado miúdo pela norma ABNT NBR NM 52 (2009). Quanto à argila expandida, utilizou-se nesse estudo àquela denominada comercialmente como 1506, por possuir granulometria parecida à da brita 0,0 material que a mesma substituiu.

\subsection{Dosagem do concreto}

Quanto à dosagem do concreto, ou seja, a quantidade de cada material da mistura, utilizou-se o método de dosagem da Associação Brasileira de Cimento Portland, visto que o mesmo pode ser aplicado para concretos de consistência plástica à fluida (AMBROZEWICZ, 2012). Assim, para o uso do método foi determinado, inicialmente, que a resistência característica esperada para o concreto aos 28 dias seria $25 \mathrm{MPa}$ e o abatimento em tronco de cone seria 100 milímetros.

Assim, foram utilizados os resultados dos ensaios de caracterização e realizado o cálculo do traço do concreto referência. A partir da proporção encontrada, foram moldados outros traços com substituição do agregado graúdo convencional por argila expandida e acréscimos de SCCA.

$\mathrm{Na}$ pesquisa desenvolvida por Barcelos et al. (2016) foi substituído o agregado graúdo convencional por argila expandida na porcentagem de $60 \%$ e, a partir disso, o concreto obtido enquadrou-se como semi-leve. Nesse contexto, para o presente estudo, optouse por analisar uma substituição de $70 \%$ visando encontrar um concreto classificado como leve. Já na pesquisa de Maycá et al. (2008) foram analisadas substituições em diferentes porcentagens, sendo que 20\%, 30\% e $40 \%$ apresentaram concretos com boas condições de trabalho. Dessa forma, optou-se por avaliar uma substituição de $30 \%$ dos agregados convencionais por argila expandida.

Ainda, optou-se por adicionar SCCA ao cimento na porcentagem de $20 \%$ gerando, assim, 5 traços para a análise dos resultados:

- Traço Referência (REF)

- Traço com 30\% de substituição (AG30\%)

- Traço com $70 \%$ de substituição (AG70\%)

- Traço com $30 \%$ de substituição e acréscimo de 20\% de SCCA $(\mathrm{AG} 30 \%+\mathrm{SCCA})$ 
- Traço com $70 \%$ de substituição e acréscimo de $20 \%$ de SCCA (AG70\% + SCCA).

\subsection{Ensaios do concreto}

A produção do concreto foi mecanizada, utilizando betoneira, já a moldagem do concreto foi realizada manualmente em corpos de prova cilíndricos, com diâmetro de $10 \mathrm{~cm}$ e altura de $20 \mathrm{~cm}$, seguindo as recomendações da norma ABNT NBR 5738 (2015). Quanto ao adensamento, tem-se que esse foi realizado manualmente com auxílio de haste metálica através de 12 golpes, sendo que o concreto é adicionado ao molde em três camadas. Anteriormente à produção, os materiais foram secos em estufa durante 24 horas, devidamente pesados. Ainda, a argila expandida foi previamente saturada a partir de sua imersão total em água, conforme indicado por Rossignolo (2009).

Ainda no estado fresco foi determinada a massa específica do concreto através da norma ABNT NBR 9833 (2009). O ensaio consiste na utilização de um recipiente com volume conhecido e igual a $20 \mathrm{dm}^{3}$, no qual é adicionado o concreto em 3 camadas adensadas com 25 golpes de haste metálica. Após, o recipiente contendo concreto é pesado e, assim, determina-se o valor para a massa específica.

Ademais, também foi realizado o ensaio de abatimento em tronco de cone seguindo as orientações da norma ABNT NBR NM 67 (1998), objetivando aproximadamente 100 $\mathrm{mm}$, como determinado no cálculo de dosagem. Assim, com o intuito de obter o abatimento determinado, foi adicionado água sempre que necessário. Dessa forma, a relação água/cimento se alterou e, possivelmente, impactou a resistência mecânica. Por fim, os corpos de prova foram desmoldados e postos em câmara úmida, para dar prosseguimento à

\section{¿unisul}

cura, onde permaneceram até a idade de rompimento.

No estado endurecido, foram realizados os ensaios de compressão axial simples seguindo a norma ABNT NBR 5739 (2018). Para a determinação dos resultados foram ensaiados 3 corpos de prova para cada traço em cada idade e, então, uma média entre os valores foi determinada. A compressão foi realizada aos 7, 28 e 91 dias e o ensaio pode ser observado na Figura 3.

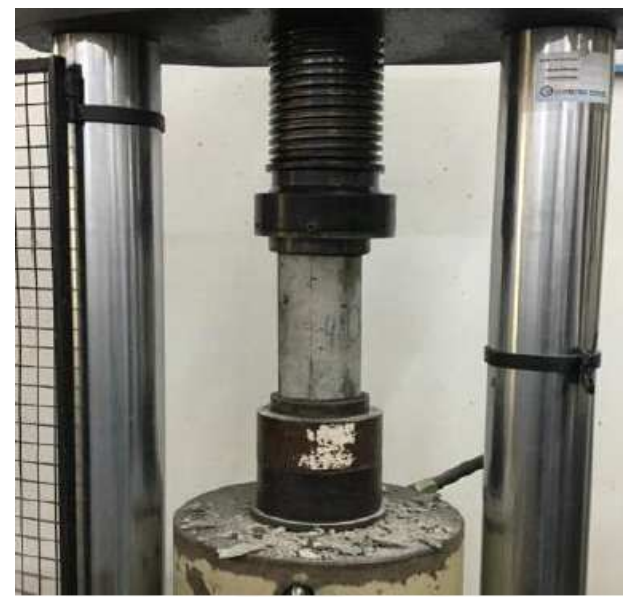

Figura 3. Ensaio de resistência à compressão axial simples. Fonte: Autoria própria (2020).

\section{RESULTADOS E DISCUSSÕES}

A fim de realizar o cálculo de dosagem pelo método da ABCP, a caracterização dos materiais foi executada. Os valores obtidos para os agregados convencionais são apresentados na Tabela 01. 
Tabela 01: Caracterização dos agregados convencionais

\begin{tabular}{lcc}
\hline \multicolumn{1}{c}{ Propriedade } & Areia Grossa & Brita 0 \\
\hline $\begin{array}{l}\text { Massa específica } \\
\left(\mathrm{kg} / \mathrm{m}^{3}\right)\end{array}$ & 2580 & 2860 \\
$\begin{array}{l}\text { Massa unitária } \\
\text { solta }\left(\mathrm{kg} / \mathrm{m}^{3}\right)\end{array}$ & 1610 & - \\
$\begin{array}{l}\text { Massa compactada } \\
\left(\mathrm{kg} / \mathrm{m}^{3}\right)\end{array}$ & - & 1510 \\
$\begin{array}{l}\text { Absorção de água } \\
(\%)\end{array}$ & - & 1,85 \\
$\begin{array}{l}\text { Módulo de finura } \\
(\mathrm{mm})\end{array}$ & 2,75 & 5,86 \\
$\begin{array}{l}\text { Diâmetro máximo } \\
(\mathrm{mm})\end{array}$ & 4,8 & 9,5 \\
\hline
\end{tabular}

Para o cimento Portland, foi determinada a massa específica e o valor obtido foi de 3,02 $\mathrm{g} / \mathrm{cm}^{3}$ e, conforme fornecido pelo fabricante, tem-se que a superfície específica desse material é, em média, igual a $4,08 \mathrm{~cm}^{2} / \mathrm{g}$. Já para a SCCA, em um estudo realizado por Marangon et al. (2013), tem-se que a massa específica do material é de aproximadamente $2,16 \mathrm{~g} / \mathrm{cm}^{3}$ e sua área específica igual a 2,11 $\mathrm{cm}^{2} / \mathrm{g}$.

A partir de uma comparação entre os valores obtidos para a superfície específica dos aglomerantes, fica evidente que a SCCA tende a consumir mais água que o cimento. Ademais, visando um melhor entendimento sobre o concreto leve e o impacto causado pela argila expandida em suas propriedades, tem-se, na Tabela 02, os valores referentes à caracterização desse material obtidos através do fabricante.
Tabela 02: Propriedades da argila expandida 1506

\begin{tabular}{lc}
\hline \multicolumn{1}{c}{ Propriedade } & $\begin{array}{c}\text { Argila Expandida } \\
\mathbf{1 5 0 6}\end{array}$ \\
\hline $\begin{array}{l}\text { Massa específica } \\
\left(\mathrm{kg} / \mathrm{m}^{3}\right)\end{array}$ & 1111 \\
$\begin{array}{l}\text { Densidade aparente } \\
\left(\mathrm{kg} / \mathrm{m}^{3}\right)\end{array}$ & $600 \pm 10 \%$ \\
$\begin{array}{l}\text { Retenção de água e ar } \\
(\%)\end{array}$ & 18 \\
$\begin{array}{l}\text { Classe granulométrica } \\
(\mathrm{mm})\end{array}$ & $6-15$ \\
Porosidade $(\%)$ & 80 \\
\hline
\end{tabular}

A partir disso, tem-se que a porosidade da argila expandida é de $80 \%$, logo, a absorção de água desse material tende a ser elevada. Ainda, esse valor está ligado à capacidade de retenção de água e ar que, em comparação à absorção de água da brita, apresenta valor cerca de 10 vezes superior. Essa diferença impacta na relação água/cimento, visto que o uso do agregado leve implica em adições de água além da calculada na dosagem a fim de manter a trabalhabilidade da mistura. Nesse contexto, para atenuar a absorção de água do novo agregado quando implementado no concreto, optou-se por présaturar o mesmo através de sua submersão em água durante 24 horas.

Já para a massa específica, o valor para a brita 0 é de $2860 \mathrm{Kg} / \mathrm{m}^{3}$, ou seja, maior que o dobro do valor referente à argila expandida, $1111 \mathrm{Kg} / \mathrm{m}^{3}$. Outrossim, evidencia-se que o agregado alternativo diminuirá a massa específica do concreto, conforme indicam as bibliografias estudadas.

Com base nos dados de caracterização apresentados, o traço obtido foi de 1:2,23:2,04:0,57 para cimento:areia:brita: água, respectivamente. Com base nisso, a substituição da brita por argila expandida ocorreu nas porcentagens de $30 \%$ e $70 \%$, e a adição de cinza de casca de arroz em $20 \%$, 
ambas em massa. Ainda, como a utilização do agregado poroso ocorreu em porcentagens significativas e em dois traços houve adição de um material com partículas finas, houveram evidentes modificações na relação água/cimento $(\mathrm{a} / \mathrm{c})$, bem como na relação água/aglomerante (a/ag), conforme a Tabela 03.

Tabela 03. Relações água/cimento e água/aglomerante obtidas

\begin{tabular}{cccc}
\hline Traço & $\begin{array}{c}\text { Fator a/c } \\
\text { calculado }\end{array}$ & $\begin{array}{c}\text { Fator } \\
\mathbf{a} / \mathbf{c} \\
\text { obtido }\end{array}$ & $\begin{array}{c}\text { Fator } \\
\mathbf{a} / \mathbf{a g}\end{array}$ \\
\hline REF & 0,57 & 0,55 & 0,55 \\
AG30\% & 0,57 & 0,59 & 0,59 \\
AG70\% & 0,57 & 0,69 & 0,69 \\
AG30\% & 0,57 & 0,59 & 0,49 \\
+ SCCA & & & \\
AG70\% & 0,57 & 0,70 & 0,70 \\
+ SCCA & & & \\
\hline
\end{tabular}

Ressalta-se, ainda, que foram considerados dois parâmetros diferentes para avaliação dos concretos estudados. O primeiro, fator a/c, considera a quantidade de água da mistura medida em relação à massa de cimento. Já o segundo, fator a/ag, considera a quantidade de água da mistura em relação à massa de aglomerante, portanto, leva em conta as parcelas de cimento e SCCA em conjunto.

A partir disso, no caso dos traços com uso de SCCA as misturas necessitaram de mais água em comparação ao concreto leve sem esse aglomerante, gerando um fator a/ag inferior ao a/c. Isso pode ser explicado pelo fato da quantidade de cimento e de aglomerante serem os denominadores das relações explicadas anteriormente, desse modo, como a SCCA foi uma adição à mistura, a quantidade de

\section{sunisul}

aglomerante fica superior à quantidade de cimento isolada, fazendo com que o resultado da divisão fique diferente para os parâmetros.

Quanto aos traços AG30\% e AG70\%, conforme esperado, houve aumento no fator a/c, sendo a segunda situação a mais crítica. Por fim, para os traços AG30\%+SCCA e AG70\%+SCCA a mesma situação é verificada.

Quanto à moldagem, o traço referência apresentou valor de a/c ligeiramente inferior ao estimado no cálculo, pois o abatimento requerido foi obtido antes da adição total da água determinada, conforme a Tabela 04, em que são apresentados os resultados do ensaio para todos os traços do estudo. Ademais, ressalta-se que, embora o abatimento tenha sido definido no cálculo como $100 \mathrm{~mm}$, há uma tolerância de $01 \mathrm{~cm}$ permitida pela norma brasileira para os resultados do ensaio.

Tabela 04: Resultados do ensaio de abatimento em tronco de cone

\begin{tabular}{cc}
\hline Traço & Abatimento \\
\hline REF & 9,7 \\
AG30\% & 9,4 \\
AG70\% & 9,8 \\
AG30\% + SCCA & 10 \\
AG70\% + SCCA & 9,1 \\
\hline
\end{tabular}

Ainda no estado fresco, quanto ao ensaio de massa específica, os resultados podem ser observados na Tabela 05 . 
Tabela 05: Resultados do ensaio de massa específica.

\begin{tabular}{cc}
\hline Traço & $\begin{array}{c}\text { Massa específica } \\
\left(\mathbf{k g} / \mathbf{m}^{3}\right)\end{array}$ \\
\hline REF & 2340 \\
AG30\% & 1950 \\
AG70\% & 1640 \\
AG30\% + SCCA & 1994 \\
AG70\% + SCCA & 1701 \\
\hline
\end{tabular}

Após observar a tabela supracitada, fica claro que a substituição do agregado fez com que a massa específica do concreto diminuísse consideravelmente, sendo essa redução diretamente proporcional à quantidade de agregado leve na mistura. Enquanto o traço referência apresentou valor igual a $2340 \mathrm{~kg} / \mathrm{m}^{3}$, os traços com argila expandida apresentaram reduções na ordem de $17 \%$ e $30 \%$ para, respectivamente, substituições de $30 \%$ e $70 \%$ do agregado convencional pelo agregado leve.

Outrossim, destaca-se que as massas específicas dos traços AG30\%+SCCA e AG70\%+SCCA ficaram ligeiramente superiores à AG30\% e AG70\%, respectivamente. Isso ocorreu devido ao fato da adição de SCCA ter promovido um aumento na quantidade de finos na mistura e, assim, maior concentração de pasta aglomerante entre os grãos.

Nesse contexto, de acordo com a definição de concreto leve de Rossignolo (2009), todos os concretos alternativos fabricados nessa pesquisa se enquadram como leves, já que o valor da massa específica é inferior a 2000 $\mathrm{kg} / \mathrm{m}^{3}$. Já para as definições de Mehta e Monteiro (2006), apenas a substituição de 70\% do agregado gera concreto leve.

\section{sunisul}

Na Tabela 06 estão dispostos os dados obtidos de resistência a compressão dos traços estudados.

Tabela 06. Resultados do ensaio de resistência à compressão em MPa.

\begin{tabular}{cccc}
\hline Traço & $\mathbf{7}$ dias & 28 dias & 91 dias \\
\hline REF & 28,0 & 40,2 & 44,3 \\
AG30\% & 22,4 & 25,8 & 27,2 \\
AG70\% & 17,2 & 18,7 & 19,2 \\
AG30\% & 24,3 & 29,5 & 33,2 \\
+ SCCA & & & \\
AG70\% & 15,7 & 21,1 & 23,4 \\
\hline
\end{tabular}

Inicialmente, ressalta-se que o objetivo do cálculo de dosagem adotado era a obtenção de $25 \mathrm{MPa}$ aos 28 dias para o traço referência. Entretanto, como pode ser observado na tabela supracitada, o valor encontrado nessa idade foi 40,2 MPa. Esse comportamento já era esperado pois o cálculo de dosagem utilizado exige correções nas primeiras moldagens, que não foram realizadas nesse estudo.

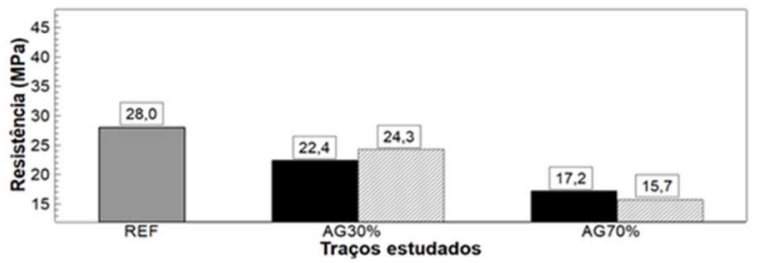

Figura 4 - Resultados do ensaio de compressão axial simples aos 7 dias. Na qual $\square$ Referência $\square$ Sem adição de SCCA $\square$ Com adição de SCCA

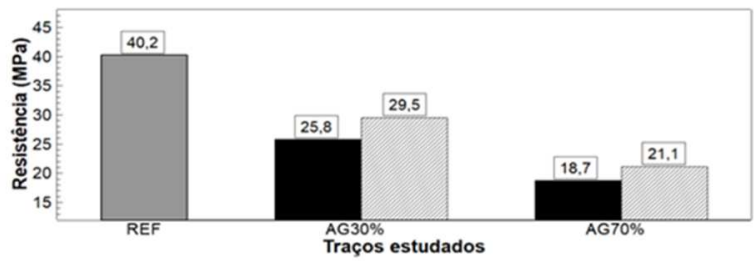

Figura 5 - Resultados do ensaio de compressão axial simples aos 28 dias. Na qual $\square$ Referência $\square$ Sem adição de SCCA $\square$ Com adição de SCCA 
Entretanto, como o objetivo principal é avaliar o comportamento dos concretos em diferentes idades, observando o crescimento de suas resistências e a diferença ao utilizar, ou não, a SCCA, essa medida não impacta negativamente nos resultados. Ademais, as Figuras 4, 5 e 6 apresentam, respectivamente, o comportamento da resistência à compressão dos concretos analisados nas idades de 7, 28 e 91 dias.

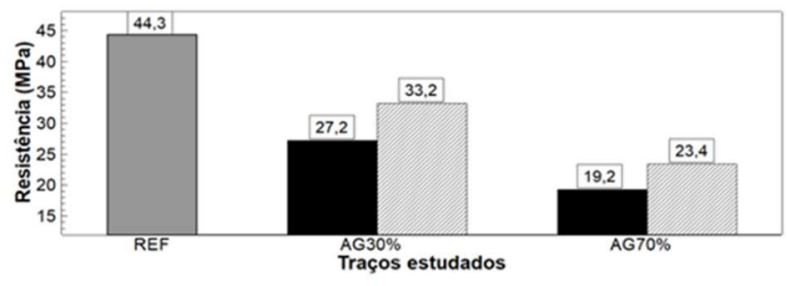

Figura 6 - Resultados do ensaio de compressão axial simples aos 91 dias. Na qual $\square$ Referência $\square$ Sem adição de SCCA $\square$ Com adição de SCCA

Analisando os gráficos é possível perceber que $o$ traço referência apresentou comportamento típico de concretos que fazem uso do cimento utilizado nessa pesquisa, $\mathrm{CP} \mathrm{V}$ ARI. Sendo assim, a mistura obteve resistência significativa na primeira idade, e manteve crescimento menor, mas ainda sim considerável, até os 28 dias, chegando a 40,2 MPa. Entretanto, após essa idade, até os 91 dias, houve baixo crescimento de resistência, apenas 4,1 $\mathrm{MPa}$.

Quanto aos concretos com argila expandida sem adição de SCCA, aos 7 dias foram encontrados resultados inferiores ao concreto referência. O traço AG30\% atingiu 22,4 MPa, cerca de $20 \%$ inferior ao traço controle na mesma idade. Já o traço AG70\% apresentou $17,2 \mathrm{MPa}$, muito inferior ao traço referência que, na mesma idade atingiu $28 \mathrm{MPa}$.

Ainda aos 7 dias, quando a SCCA foi adicionada, houve aumento de $2 \mathrm{MPa}$ no traço AG30\% + SCCA e diminuição de resistência no traço AG70\% + SCCA. Essa ocorrência pode ser explicada pela cinza que, por ser uma pozolana, tem reações mais lentas, sendo

\section{sunisul}

necessário avaliar sua influência em idades mais avançadas.

Já aos 28 dias, foi observado crescimento significativo para o concreto referência que atingiu resistência de 40,2 $\mathrm{MPa}$, ou seja, cerca de $12 \mathrm{MPa}$ a mais se comparado à idade de análise anterior, 7 dias, diferentemente do que ocorreu para os traços que utilizaram argila expandida. Para AG30\% e AG70\%, o crescimento foi de apenas 3,4 MPa e 1,5 MPa, respectivamente, ou seja, muito inferior ao concreto referência na mesma idade.

Ademais, quanto à utilização de SCCA, foi observado que esse material contribuiu no aumento da resistência, conforme esperado. Isso porque houve incremento de cerca de 5,2 $\mathrm{MPa}$ e 5,4 MPa aos traços AG30\% + SCCA e AG70\% + SCCA, quando comparado à idade de 7 dias. Assim, fica clara a contribuição da cinza já aos 28 dias, em que os traços de concreto leve que a utilizaram obtiveram melhor desempenho.

Nesse contexto, aos 28 dias o traço com $30 \%$ de argila expandida atingiu a resistência de cálculo, $25 \mathrm{MPa}$, utilizando ou não a SCCA como adição ao cimento. Já para AG70\% e AG70\% + SCCA, é perceptível que, embora a cinza tenha contribuído no ganho de resistência para o último, esses concretos não atingiram nem mesmo o determinado pelo cálculo.

Entretanto, de acordo com Mehta e Monteiro (2006), as substituições de $70 \%$ podem ser consideradas concretos estruturais leves, uma vez que os valores de massa específica estão abaixo de $1850 \mathrm{Kg} / \mathrm{m}^{3}$ e a resistência à compressão é maior que $17 \mathrm{MPa}$. O mesmo não pode ser observado para as misturas de 30\%, já que as mesmas não obtiveram redução de peso tão significativa quando comparadas ao concreto referência.

Por fim, apenas aos 91 dias foi possível verificar o impacto da utilização de SCCA no 
concreto, devido à velocidade reduzida das reações pozolânicas. Assim, os traços que utilizaram esse material apresentaram melhor desempenho, mas, ainda sim, resultados inferiores e distantes aos valores encontrados para referência. Nesse sentido, ao analisar os concretos com SCCA e também aqueles sem a adição desse material, foi observado aumento maior que $20 \%$ na resistência final aos 91 dias.

A partir disso, foi verificado que todos os traços com substituição do agregado pela argila expandida apresentaram valores inferiores se comparados ao concreto referência, possivelmente pela menor resistência do agregado leve e, também, pela porosidade da matriz de cimento devido aos altos fatores água/cimento encontrados. Já quanto ao uso de SCCA, sua utilização como acréscimo ao cimento auxiliou nas resistências finais, devido às características pozolânicas do material, sendo possível, ainda, um crescimento de resistência diferenciado em idades mais avançadas.

\section{CONCLUSÕES}

O presente artigo expôs uma análise acerca do concreto leve produzido com argila expandida, bem como com adições de sílica da cinza da casca de arroz, avaliando o desempenho mecânico quanto à compressão e determinando a massa específica $\mathrm{e}$ consistência. Em relação ao estado fresco, houve uma redução do peso, se comparado ao traço referência, de $17 \%$ e $30 \%$ para os traços AG30\% e AG70\%, respectivamente. Sendo que as adições de SCCA não influenciaram de forma significativa nessa propriedade.

Ainda acerca da massa específica, foi possível concluir que segundo Rossignolo (2009), os traços com argila expandida podem ser classificados como leves. Outrossim, de acordo com Mehta e Monteiro (2006), apenas
AG70\% e AG70\% + SCCA podem ser definidos como leves.

Além disso, a trabalhabilidade das misturas foi assegurada por acréscimos de água, impactando na relação água/cimento. Enquanto o traço REF apresentou valor igual a 0,55 para essa propriedade, o traço AG70\% + SCCA, por exemplo, atingiu 0,70. Isso ocorreu devido à grande porosidade do agregado alternativo utilizado e, também, pela maior superfície específica da pozolana incorporada. Nessa perspectiva, essa situação aumentou ainda mais a quantidade de vazios na pasta de cimento, impactando diretamente na resistência mecânica dos concretos produzidos.

Em relação ao ensaio de resistência à compressão axial simples, os valores obtidos para os concretos alternativos foram inferiores. No que tange ao emprego de argila expandida, verificou-se que essa redução é diretamente proporcional à porcentagem de substituição analisada e limita a resistência obtida em todas as idades de rompimento.

Já quanto ao uso da SCCA ficou evidente a contribuição dessa à mistura, principalmente em idades avançadas, como aos 91 dias. Nesse sentido, para o aumento de resistência de concretos alternativos, a SCCA é uma possibilidade viável do ponto de vista técnico e ambiental, ao passo que evita o descarte irregular desse resíduo promovendo a sustentabilidade não só no processo de beneficiamento do arroz, como também na indústria da construção civil brasileira.

Por fim, os resultados permitem o uso dessas misturas para a confecção de peças com funções estruturais, desde que tomados os devidos cuidados. A partir dessas informações, conclui-se que o uso da argila expandida em conjunto com a SCCA pode trazer benefícios ao setor da construção civil ao passo que reduz 
os esforços nas estruturas, através da redução da massa específica do concreto.

\section{REFERÊNCIAS}

Ambrozewicz, P. H. L., 2012. Materiais de construção: normas, especificações, aplicação e ensaios de laboratório. PINI, São Paulo.

ABNT, Associação brasileira de normas técnicas. NBR NM 35. Agregados leves para concreto estrutural - Especificação. Rio de Janeiro, 1995. 8p

ABNT, Associação brasileira de normas técnicas. NBR NM 45. Agregados Determinação da massa unitária e do volume de vazios. Rio de Janeiro, 2006. 8p.

ABNT, Associação brasileira de normas técnicas. NBR NM 52. Agregado miúdo Determinação de massa específica e massa específica aparente. Rio de Janeiro, 2009. 6p.

ABNT, Associação brasileira de normas técnicas. NBR NM 53. Agregado graúdo Determinação de massa específica, massa específica aparente e absorção de água. Rio de Janeiro, 2009. 8p.

ABNT, Associação brasileira de normas técnicas. NBR NM 67. Concreto Determinação da consistência pelo abatimento do tronco de cone. Rio de Janeiro, 1998. 8p.

ABNT, Associação brasileira de normas técnicas. NBR NM 248. Agregados Determinação da composição granulométrica. Rio de Janeiro, 2003. 3p.

ABNT, Associação brasileira de normas técnicas. NBR 5738. Concreto - Procedimento para moldagem e cura de corpos de prova. Rio de Janeiro, 2016. 9p.

ABNT, Associação brasileira de normas técnicas. NBR 5739. Concreto - Ensaio de compressão de corpos-de-prova cilíndricos. Rio de Janeiro, 2018. 9p.
ABNT, Associação brasileira de normas técnicas. NBR 7211. Agregados para concreto - Especificação. Rio de Janeiro, 2009. 9p.

ABNT, Associação brasileira de normas técnicas. NBR 9833. Concreto fresco Determinação da massa específica, do rendimento e do teor de ar pelo método gravimétrico. Rio de Janeiro, 2009. 7p.

ABNT, Associação brasileira de normas técnicas. NBR 12655. Concreto de cimento Portland - Preparo, controle, recebimento e aceitação - Procedimento. Rio de Janeiro, 2015. 23p.

ABNT, Associação brasileira de normas técnicas. NBR 16605. Cimento Portland e outros materiais em pó - Determinação da massa específica. Rio de Janeiro, 2017. 4p.

Barcelos, J. L. et al., 2016. Confecção de concreto estrutural leve substituindo parte dos agregados graúdos por argila expandida. Anais do $60^{\circ}$ Congresso Brasileiro de Cerâmica. Águas de Lindóia, São Paulo.

Bauer, L. A. F., 2008. Materiais de construção. 5. ed. LTC Editora S.A., Rio de Janeiro.

Cinexpan, 2015. Ficha Técnica - Argila Expandida 1506.

https://www.cinexpan.com.br/argilaexpandida-1506-cinexpan.html (Acesso em: 01/02/2021).

Folleto, L.E. et al. 2005. Aplicabilidade das cinzas da casca de arroz. Química Nova, Santa Maria (RS), p. 1055-1060.

Helene P., Andrade, T. 2010. Concreto de Cimento Portland. In: Geraldo Cechella Isaia (org.). Materiais de Construção Civil e Princípios de Ciência e Engenharia de Materiais. Ibracon, São Paulo.

Maycá J., et al. 2008. Contribuição ao estudo da argila expandida nacional como alternativa de agregado graúdo para concretos leves estruturais (CLE). Artigo do Curso de 


\section{sunisul sing}

Especialização em Construção Civil.

Universidade Federal do Rio Grande do Sul.

Porto Alegre.

Mehta, P. K. 1992. Rice Husk ash - A unique suplementary cementing material. In: Advances in Concrete Technology. CANMET. Ottawa, p. $407-431$.

Mehta, P. K., Monteiro, P. J. M., 2008. Concreto: microestrutura, propriedades e materiais. 3. ed. IBRACON, São Paulo.

Moncada, J. E. C. M. et al. 2019. Estudo da adição de argila expandida e EPS como agregados na elaboração de concreto leve. Revista Teccen. Rio de Janeiro.

Moravia, W. G.et al. 2006. Caracterização microestrutural da argila expandida para a aplicação como agregado em concreto estrutural leve. Cerâmica [online]. São Paulo. Vol. 52, n. 322, p.193-199.

Neville, A. M., 2016. Propriedades do Concreto. 5.ed. Bookman, Porto Alegre.

Rossignolo, J. A., 2009. Concreto Leve Estrutural: produção, propriedades, microestrutura e aplicações. Editora PINI, São Paulo.

Schimanowski, E. R. Z. et al. 2019. Concreto com substituição de cimento por cinza da casca de arroz. Anais do Salão do Conhecimento da Universidade Regional do Noroeste do Estado do Rio Grande do Sul, Ijuí (RS).

Sobral, H. S. 2000. Propriedades do concreto fresco. Associação Brasileira de Cimento Portland, 5.ed. São Paulo, 32p.

Zhang, M. H., Malhotra, V.M. 1996. HighPerformance Concrete Incorporating Rice Husk Ash as a Supplementary Cementing Material. ACI Materials Journal, United States. P. 629-636.

Zhang, M. H. et al. 1996. Rice-husk ash paste and concrete: Some aspects of hydration and the microstructure of the interfacial zone between the aggregate and paste. Cement and Concrete Research. United States.1996, 26, 963.

\section{Agradecimentos}

Os autores agradecem ao MEC-Sesu pela bolsa de pesquisa no Programa de Educação Tutorial (PET) de Engenharia Civil da Universidade Regional do Noroeste do Estado do Rio Grande do Sul e, também, ao Laboratório de Engenharia Civil da mesma instituição. 